\title{
Proceeding
}

Supplementary Issue: Winter Conferences of Sports Science. Costa Blanca Sports Science Events, 22-23 March 2021. Alicante, Spain.

\section{The effect of a selected physiotherapy program on pelvic deviations in cases of supple flat feet}

\author{
FATIMA A. H. ALOWAIS ${ }^{1,2}$, TAMER M. SHOUSHA 3,4 \\ ${ }^{1}$ Physical Therapy Department, Al Qassimi Hospital, Sharjah, United Arab Emirates \\ ${ }^{2}$ BSc PT Department of Physical Therapy, CHS, University of Sharjah, United Arab Emirates \\ ${ }^{3}$ Department of Physical Therapy, CHS, University of Sharjah, United Arab Emirates \\ ${ }^{4}$ Department of Physical Therapy for Musculoskeletal Disorders and its Surgery, Faculty of Physical Therapy, \\ Cairo University, Egypt
}

\begin{abstract}
Supple flat feet is frequent condition having diverse effects on the entire lower limb kinetic chain including the pelvis. Thus, this study was conducted to compare the effects of an 8-weeks, conservative physiotherapy treatment program to a medial arch support on pelvic deviation. A prospective, randomized, single-blind, controlled trial was conducted at the Physiotherapy department, college of health sciences, University of Sharjah. One hundred male participant were assed for pelvic obliquity and torsion before and after 8 weeks of the either an exercise program or using an insole for medial arch support. Group $(A)$ received progressive short feet exercises, while group (B) used the insole for medial arch support. The study results revealed a statistically significant decrease in pelvic obliquity and pelvic torsion in the exercise group (A) only with values of ( $p=.030$ and .035$)$ respectively. No statistically significant difference was found within the insole group (B). Between groups analysis revealed a significant difference in favour of group (A) compared to group (B) for both pelvic obliquity $(p=.039)$ and torsion $(p=.036)$ respectively). To sum it up, short feet exercises were more effective in decreasing pelvic deviations in cases of bilateral supple flat feet.
\end{abstract}

Keywords: Supple flat feet; Pelvic obliquity; Pelvic torsion; DIERS; Formetric.

Cite this article as:

Alowais, F.A.H., \& Shousha, T.M. (2021). The effect of a selected physiotherapy program on pelvic deviations in cases of supple flat feet. Journal of Human Sport and Exercise, 16(3proc), S874-S882. https://doi.org/10.14198/jhse.2021.16.Proc3.04

Corresponding author. Department of Physical Therapy, CHS, University of Sharjah, United Arab Emirates.

E-mail: tshousha@sharjah.ac.ae

Abstract submitted to: Winter Conferences of Sports Science. Costa Blanca Sports Science Events, 22-23 March 2021. Alicante, Spain.

JOURNAL OF HUMAN SPORT \& EXERCISE ISSN 1988-5202.

(c) Faculty of Education. University of Alicante.

doi:10.14198/jhse.2021.16.Proc3.04

S874 | 2021| Proc3 | VOLUME 16

C 2021 University of Alicante 


\section{INTRODUCTION}

The positional attitudes of the Pelvis depend on the alignment of the lower limb's joints during movements assumed in the closed kinematic chain (Pinto et al., 2008). Any change in lower limbs results in postural alterations of the pelvic girdle and was reported to enhance the risk of secondary complaints as low back pain (Eldesoky \& Abutaleb, 2015; Khamis \& Yizhar, 2007). The posture of the feet in standing was reported to influence pelvic alignment and spinal posture in standing position (Eldesoky \& Abutaleb, 2015; Rothbart \& Estabrook, 1988). Flatfoot is a frequently encountered pathology and often debilitating chronic foot and ankle conditions (Legaye et al., 1998; Pinney \& Lin, 2006). As flat feet include decreased medial arch, talar adduction and medial rotation, calcaneal eversion, and forefoot abduction (Degenhardt et al., 2017; Lee et al., 2005), the alterations in foot posture will eventually lead to alterations of the pelvic and spine alignments (Khamis \& Yizhar, 2007; Lee et al., 2005; Levine \& Whittle, 1996; Tweed et al., 2008) which resulted from the additional stress placed on the ligaments, joints, and muscles engaged in preservation of standing posture (Aebi, 2005). The presence of adduction of the talus and the eversion of the calcaneus cause the lower limb to assume an internal rotation position with reduction in limb length and consequently alter the pelvis alignment (Botte, 1981; Haight et al., 2005; McPartland et al., 1997; Snijders et al., 1993). In addition, bilateral calcaneal eversion produces internal rotation of the lower limb and may lead to increased pelvic anteversion and consequently may cause lumbar hyper lordosis (Botte, 1981; Eldesoky \& Abutaleb, 2015; Haight et al., 2005). To our knowledge, only one study investigated the effect of flatfeet on the sagittal and frontal planes of pelvic postures (Eldesoky \& Abutaleb, 2015), but no studies were designed to investigate the effects of therapeutic or orthotic treatments for fleet feet on pelvic alignment.

The purpose of this study was to compare the effects of an 8-weeks, conservative physiotherapy treatment program to a medial arch support on pelvic deviations in cases of supple flat feet among male students in the college of health sciences in the University of Sharjah (UOS) in Sharjah, United Arab Emirates.

\section{METHODOLOGY}

The research is designed as a randomized controlled trial that compared 2 groups of participants. Group A (exercise group) included participants who joined a short foot exercise protocol for a period of 8 weeks (Kim \& Kim, 2016; Unver et al., 2019). While group B (Insole group) involved participants receiving a medial arch support to be used during the same period (Hsieh et al., 2018). The research is performed between March 2020 and February 2021. This research study was approved by the University of Sharjah REC committee. Reference number: REC-20-02-14-01-S.

\section{Participants}

A total of (127) male participants were assessed for eligibility with the inclusion criteria of the study. Of these, (21) did not meet the study criteria or refused to participate and thus were excluded. Finally, 100 students participated in the study [Figure 1]. All participants selected were students in the University of Sharjah, Sharjah, UAE. Their ages ranged from 18-25 years and their body mass index [BMI] did not exceed $24 \mathrm{~kg} / \mathrm{m}^{2}$. All participants were males suffering from supple flat feet (Haight et al., 2005; Khamis \& Yizhar, 2007) with BMl not exceeding $24.9 \mathrm{~kg} / \mathrm{m}^{2}$.

Participants were excluded from the study, if they were diagnosed with fixed pronated feet, Hip Anteversion, Secondary complications such as: spondylosis, disc, posterior tibial tendinitis, calcaneal spur, hallux rigidus and valgus, musculoskeletal injuries / deformities, lower limb operation/surgery within the last 6 months or failed to complete an informed consent form. 


\section{Randomization}

Anonymity of participants' data was assured by coding of all data. Assigning participants to groups was conducted by a blinded and an independent research assistant. Randomization [Figure 1] was done using sealed envelopes that contain numbers chosen by a random number generator, each participant independently chooses an envelope. Randomization was restricted to permuted blocks of different sizes to ensure that equal numbers will be allocated to each group. Each random permuted block was transferred to a sequence of consecutively numbered, sealed, opaque envelopes stored in a drawer kept locked until required. Only one member of the research group will be assigned to randomize the cases in the envelopes and inform participants about the intervention after choosing the envelope. As each participant formally entered the trial the researcher opened the next envelope in sequence in the presence of the patient.

- Participants were blinded to their intervention groups; they did not know what treatment they will be receiving.

- Participants were blinded from results, only researchers will view the results that will be kept on the primary investigator's computer that is secured by a password.

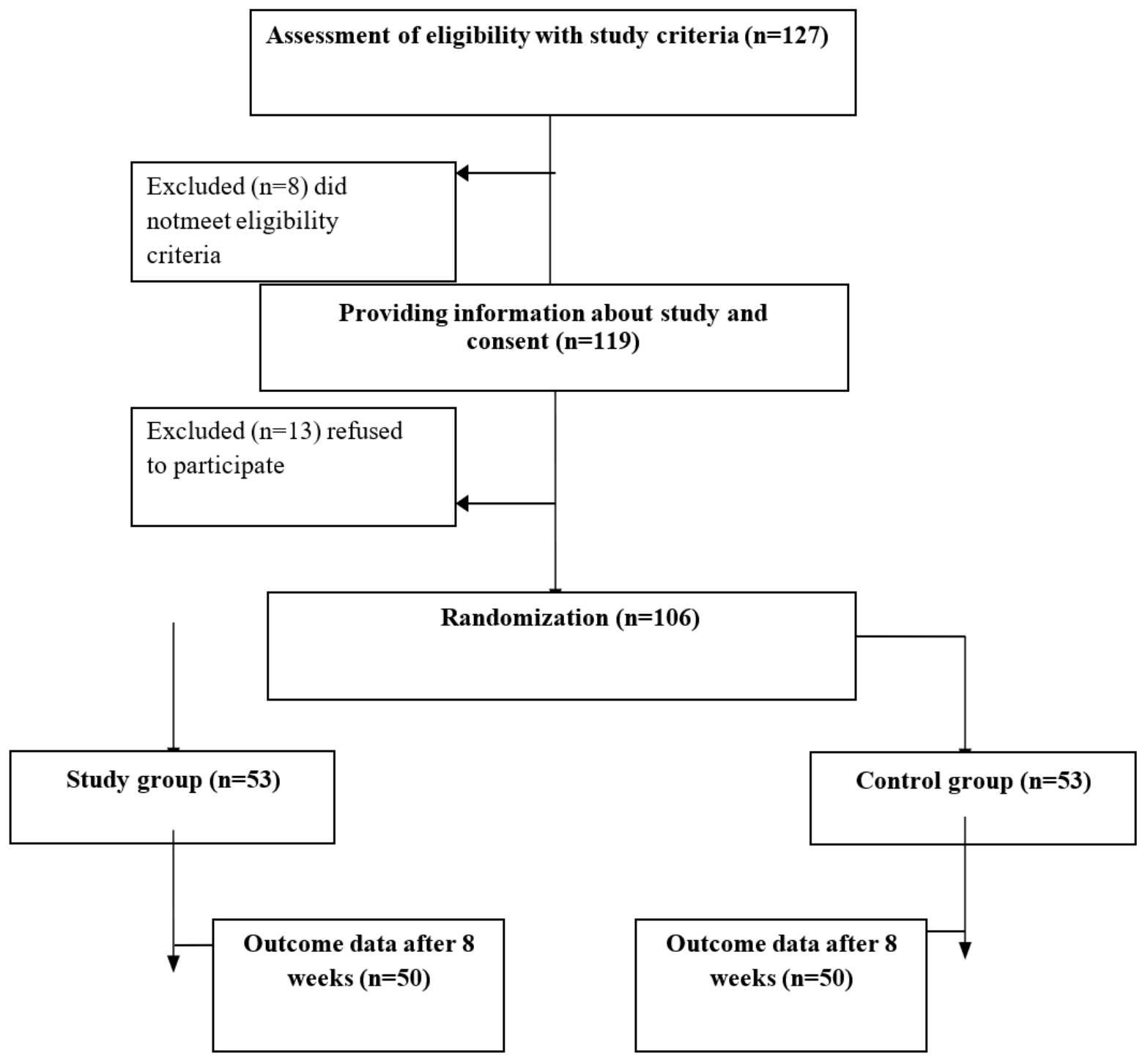

Figure 1. Randomization, participants' flow chart. 


\section{Intervention procedure}

The intervention consists of two components based on the study group, the first one was an arch support insole that is made of foam for cushioning and comes in different sizes to be individually distributed [Figure 2] (Hsieh et al., 2018). The second treatment was the physiotherapy program of short foot exercise (SFE). The group that received the selective physiotherapy program were instructed to sit on a height-adjustable chair and bend the hip joint, knee joints, and ankle joints to $90^{\circ}$ and a towel was placed below the feet. Thereafter, the subject was instructed to pull the head of the first metatarsal bone toward the heel without bending the toes like picking up a pencil or marble from the floor using the plantar side of the foot and maintain the state for 20 seconds to form the medial longitudinal arch [Figure 3] (Kim \& Kim, 2016). Exercises were done daily for 8 weeks (Unver et al., 2019).

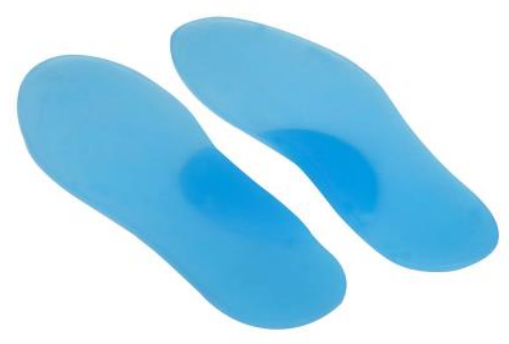

Figure 2. Shoe insoles.
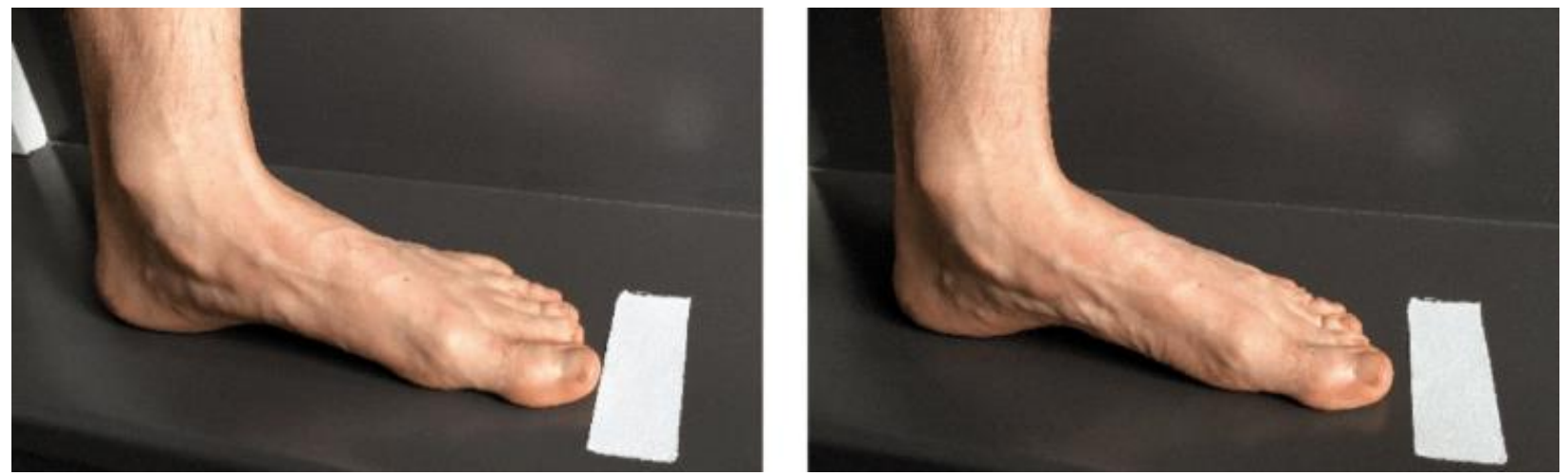

Figure $3(A$ and $B)$ : The short foot exercise. A: Starting rest position and B: Intrinsic foot muscles activated. Please note the flexion of the first phalange while activating the intrinsic foot muscles and the augmented distance between the tiptoe and the tape due to foot shorten.

Figure 3. Short foot exercises.

\section{Outcome measure}

Main outcome: The pelvic obliquity and torsion using DIERS formetric (Degenhardt et al., 2017; Eldesoky \& Abutaleb, 2015).

DIERS formetric

All assessments were performed by the second researcher at the physiotherapy department, college of health sciences, University of Sharjah. Each subject was examined in standing upright posture with both feet bared in a neutral position at a distance of 2 meter in front of the 3D scanning system camera. The patient's back 
surface lied completely bare in order to avoid disturbing image structures. The column of instrument height was adjusted according to the subject height to move the relevant parts of the patient's back into the centre of the control monitor. A multitude of light sections is projected on the patient's back from a different direction than that of the optical. The best moment for releasing image capture was the slightly breathed out state. Each subject was asked to breathe normally. The moment of breathing out will be observed on the control monitor. The patient is then asked to stop breathing for seconds while image capture was released. The scanning time is very short $(40 \mathrm{~ms})$ in order to eliminate movement artifact.

The automatic anatomical landmarks localization which were the vertebra prominent and the iliac spine in the pelvic region were the basis for an automatic reconstruction of three-dimensional dorsal surface of the sagittal back and pelvic shape that provided a set of shape parameters characterizing the back and pelvis profile. The evaluated parameters for participants include pelvic alignment in the sagittal plane and frontal plane in the form of pelvic inclination and pelvic tilt angles, respectively, after being calculated and recorded from Formetric instrument (Degenhardt et al., 2017; Eldesoky \& Abutaleb, 2015; Pinto et al., 2008).

\section{Supple flat feet assessment}

Supple flat foot was assessed by observation of the medial longitudinal arch during standing on the toes (Haight et al., 2005; Khamis \& Yizhar, 2007).

The examiner observed the participant's feet when they were seated with their feet off the ground, standing, and while they were ambulating. The participants were examined for the positions of their heels, subtalar joint, forefeet, and the medial arches. Observation of the subjects having flatfeet in standing and walking revealed heel valgus, low arch, commonly forefoot abduction and supination. The subtalar joint is commonly in the over pronated position in stance and may be even more so on walking. If any of the participants had flatfeet, the examiner detected whether it is bilateral or unilateral, while observation of the normal subjects revealed normal heel position and normal arch height. To differentiate between flexible and rigid flatfeet among the participants with flatfeet the authors used the single-heel raise test. Each subject was asked to stand on tiptoes of one foot then repeat the same procedure for the other foot. In subjects with flexible flat feet, the arch re-appeared and the calcaneus demonstrated normal inversion when viewed from behind (Arangio et al., 2004; Eldesoky \& Abutaleb, 2015; Haight et al., 2005; Levinger et al., 2010).

\section{Data analysis}

A total of 90 participants were deemed necessary for this study. Test size estimation was performed before the investigation utilizing G*POWER statistical programming.

Sample size justification: To find a prevalence of at least $30 \%$ with a significant level of .05 (two-sided) and a power of $80 \%$.

An excess of $20 \%$ was considered to account for any participant that chooses to withdraw or drops out.

For statistical analysis of the date, we will be using the IBM SPSS statistics version 21.

As for the descriptive statistics " demographic data" the homogeneity prior analysis.

A one-way ANOVA was used to detect within group and between group differences. 


\section{RESULTS}

One hundred male participants with bilateral supple flat feet were randomized and assigned into 2 equal groups. Data extracted from 50 participant in each group was analysed after completion of the intervention procedure. There were no statistically significant differences $(p>.05)$ between participants in both groups concerning age, weight, height and BMI (Table 1).

Table 1. Physical characteristics of participants in each group.

\begin{tabular}{lccc}
\hline Items & SFE Group (A) & Insole Group (B) & p-value \\
\hline Age (year) & $19.8 \pm 2.1$ & $20.2 \pm 1.97$ & .72 \\
Weight (KG) & $71.2 \pm 6.2$ & $74 \pm 3.05$ & .512 \\
Height (Cm) & $176 \pm 5.6$ & $176.5 \pm 4.85$ & .861 \\
BMI (Kg/m²) & $22.02 \pm 1.8$ & $22.7 \pm 1.04$ & .515 \\
\hline Deta & &
\end{tabular}

Data presented as mean \pm standard deviation. ${ }^{*} p$-value $<.05$ : significant. $\mathrm{Kg}=\mathrm{kilogram} . \mathrm{Cm}=$ centimetre. $\mathrm{kg} / \mathrm{m}^{2} \mathrm{kilogram} / \mathrm{meter}^{2}$.

Statistical investigations applying one- way ANOVA was used to analyse within and between group differences.

The baseline assessment revealed no statistically significant difference between groups regarding both pelvic torsion and obliquity.

Within groups, the analysis revealed a statistically significant decrease in pelvic obliquity and pelvic torsion in the exercise group $(A)$ only $(p<.05)$ with values of $(p=.030$ and .035$)$ respectively. No statistically significant difference was found within the insole group (B).

Regarding between groups, the analysis revealed that there was a significant difference in favour of group (A) compared to group (B) after completing the intervention procedure for both pelvic obliquity $(p=.039)$ and torsion $(p=.036)$ respectively (Table 2$)$.

Table 2. Between group analysis.

\begin{tabular}{|c|c|c|c|c|}
\hline Dependent Variable & & Group A (Mean \pm SD) & Group B (Mean \pm SD) & $p$-value \\
\hline & Base line & $0.79 \pm 2.83$ & $0.86 \pm 2.59$ & .089 \\
\hline Pelvic obliquity & $\begin{array}{l}\text { Post } 8 \text { weeks } \\
p \text {-value }\end{array}$ & $\begin{array}{c}0.56 \pm 1.31 \\
.030^{*}\end{array}$ & $\begin{array}{c}0.76 \pm 2.40 \\
.092\end{array}$ & $.039^{\star}$ \\
\hline & Base line & $23.1 \pm 1.54$ & $22.76 \pm 1.95$ & .079 \\
\hline Pelvic torsion & $\begin{array}{l}\text { Post } 8 \text { weeks } \\
p \text {-value }\end{array}$ & $\begin{array}{c}20.1 \pm 0.76 \\
.035^{\star}\end{array}$ & $\begin{array}{c}21.67 \pm 0.86 \\
.063\end{array}$ & $.036^{*}$ \\
\hline
\end{tabular}

\section{DISCUSSION}

The purpose of this study was to identify the effect of a selected physiotherapy treatment on pelvic obliquity and torsion in cases of supple flat feet among University of Sharjah male students.

Because of the excess pronation individuals develop compensatory mechanisms to compensate for the changes that occur consequently affecting the pelvic alignment. 
The baseline data revealed the presence of pelvic obliquity and torsion in all subjects suffering from supple flat feet, which came in accordance with (Eldesoky \& Abutaleb, 2015) but with no significant differences between both groups.

Following 8 weeks, the insole group showed no significant difference in pelvic obliquity. Although previous literature reported improvements in the pelvic deviations with using insoles (Kuo et al., 2020; Park, 2017), we believe that any potential effect could not have been detected as the testing was done bear feet. This is attributed to the direct effect of the orthosis on improving lower limb alignment in cases of flat feet (Park, 2017). Similarly, pelvic torsion did not show any significant difference as well. This might also be attributed that insoles did not significantly change the lumbopelvic kinematics when compared with subject without arch support (Kuo et al., 2020).

On the other hand, within group analysis revealed a statistically significant difference for the exercise group with regards to pelvic obliquity $(p=.030)$ and pelvic torsion $(p=.035)$ respectively. This can be explained by the effect of short foot exercising in improving the medial longitudinal arch (Kim \& Kim, 2016) and consequently restoring the lower limb and pelvic relationship. In addition, it was also reported that six-week short-foot exercises reduces navicular drop and foot pronation (Unver et al., 2019).

Such improvement in the medial arch would be directed to improve the Short foot exercises should be utilized in cases of excessive pronation of the foot (McKeon \& Fourchet, 2015; Unver et al., 2019; Yazdani et al., 2018).

Subjects with over pronation were reported previously to have a greater anterior pelvic tilt during $20 \%-80 \%$ of the stance phase (Yazdani et al., 2018).

\section{CONCLUSION}

Any relationship between pelvic obliquity and subtle flatfeet should be assessed and implemented during physical therapy assessment and treatment.

\section{Study limitations}

There were limited literature resources regarding the topic of interest. In addition, the study did not consider gender differences as only male students were included in this study.

\section{REFERENCES}

Aebi, M. (2005). The adult scoliosis. European Spine Journal, 14(10), 925-948. https://doi.org/10.1007/s00586-005-1053-9

Arangio, G. A., Reinert, K. L., \& Salathe, E. P. (2004). A biomechanical model of the effect of subtalar arthroereisis on the adult flexible flat foot. Clinical Biomechanics, 19(8), 847-852. https://doi.org/10.1016/j.clinbiomech.2003.11.002

Botte, R. R. (1981). An interpretation of the pronation syndrome and foot types of patients with low back pain. Journal of the American Podiatric Medical Association, 71(5), 243-253. https://doi.org/10.7547/87507315-71-5-243

Degenhardt, B., Starks, Z., Bhatia, S., \& Franklin, G.-A. (2017). Appraisal of the DIERS method for calculating postural measurements: an observational study. Scoliosis and Spinal Disorders, 12(1), 1-11. https://doi.org/10.1186/s13013-017-0134-y 
Eldesoky, M. T., \& Abutaleb, E. E. (2015). Influence of bilateral and unilateral flatfoot on pelvic alignment. International Journal of Medical and Health Sciences, 9(8), 641-645.

Haight, H. J., Dahm, D. L., Smith, J., \& Krause, D. A. (2005). Measuring standing hindfoot alignment: reliability of goniometric and visual measurements. Archives of Physical Medicine and Rehabilitation, 86(3), 571-575. https://doi.org/10.1016/j.apmr.2004.05.014

Hsieh, R.-L., Peng, H.-L., \& Lee, W.-C. (2018). Short-term effects of customized arch support insoles on symptomatic flexible flatfoot in children: A randomized controlled trial. Medicine, 97(20). https://doi.org/10.1097/MD.0000000000010655

Khamis, S., \& Yizhar, Z. (2007). Effect of feet hyperpronation on pelvic alignment in a standing position. Gait \& Posture, 25(1), 127-134. https://doi.org/10.1016/j.gaitpost.2006.02.005

Kim, E.-K., \& Kim, J. S. (2016). The effects of short foot exercises and arch support insoles on improvement in the medial longitudinal arch and dynamic balance of flexible flatfoot patients. Journal of Physical Therapy Science, 28(11), 3136-3139. https://doi.org/10.1589/jpts.28.3136

Kuo, F. C., Cai, D. C., \& Liau, B. Y. (2020). Foot Arch Support Effect on Lumbo-Pelvic Kinematics and Centre of Pressure Excursion During Stand-to-Sit Transfer in Different Foot Types. Journal of Medical and Biological Engineering, 40(2), 169-178. https://doi.org/10.1007/s40846-019-00499-2

Lee, M. S., Vanore, J. V, Thomas, J. L., Catanzariti, A. R., Kogler, G., Kravitz, S. R., Miller, S. J., \& Gassen, S. C. (2005). Diagnosis and treatment of adult flatfoot. The Journal of Foot and Ankle Surgery, 44(2), 78-113. https://doi.org/10.1053/j.jfas.2004.12.001

Legaye, J., Duval-Beaupere, G., Hecquet, J., \& Marty, C. (1998). Pelvic incidence: a fundamental pelvic parameter for three-dimensional regulation of spinal sagittal curves. European Spine Journal, $7(2)$, 99-103. https://doi.org/10.1007/s005860050038

Levine, D., \& Whittle, M. W. (1996). The effects of pelvic movement on lumbar lordosis in the standing position. Journal of Orthopaedic \& Sports Physical Therapy, 24(3), 130-135. https://doi.org/10.2519/jospt.1996.24.3.130

Levinger, P., Murley, G. S., Barton, C. J., Cotchett, M. P., McSweeney, S. R., \& Menz, H. B. (2010). A comparison of foot kinematics in people with normal-and flat-arched feet using the Oxford Foot Model. Gait \& Posture, 32(4), 519-523. https://doi.org/10.1016/j.gaitpost.2010.07.013

McKeon, P. O., \& Fourchet, F. (2015). Freeing the foot. Integrating the foot core system into rehabilitation for lower extremity injuries. Clinics in Sports Medicine, 34(2), 347-361. https://doi.org/10.1016/i.csm.2014.12.002

McPartland, J. M., Brodeur, R. R., \& Hallgren, R. C. (1997). Chronic neck pain, standing balance, and suboccipital muscle atrophy--a pilot study. Journal of Manipulative and Physiological Therapeutics, 20(1), 24-29.

Park, K. (2017). Effects of wearing functional foot orthotic on pelvic angle among college students in their 20s with flatfoot. Journal of Physical Therapy Science, 29(3), 438-441. https://doi.org/10.1589/jpts.29.438

Pinney, S. J., \& Lin, S. S. (2006). Current concept review: acquired adult flatfoot deformity. Foot \& Ankle International, 27(1), 66-75. https://doi.org/10.1177/107110070602700113

Pinto, R. Z. A., Souza, T. R., Trede, R. G., Kirkwood, R. N., Figueiredo, E. M., \& Fonseca, S. T. (2008). Bilateral and unilateral increases in calcaneal eversion affect pelvic alignment in standing position. Manual Therapy, 13(6), 513-519. https://doi.org/10.1016/i.math.2007.06.004

Rothbart, B. A., \& Estabrook, L. (1988). Excessive pronation: a major biomechanical determinant in the development of chondromalacia and pelvic lists. J Manipulative Physiol Ther, 11(5), 373-379.

Snijders, C. J., Vleeming, A., \& Stoeckart, R. (1993). Transfer of lumbosacral load to iliac bones and legs: Part 1: Biomechanics of self-bracing of the sacroiliac joints and its significance for treatment and exercise. Clinical Biomechanics, 8(6), 285-294. https://doi.org/10.1016/0268-0033(93)90002-Y 
Tweed, J. L., Campbell, J. A., \& Avil, S. J. (2008). Biomechanical risk factors in the development of medial tibial stress syndrome in distance runners. Journal of the American Podiatric Medical Association, 98(6), 436-444. https://doi.org/10.7547/0980436

Unver, B., Erdem, E. U., \& Akbas, E. (2019). Effects of short-foot exercises on foot posture, pain, disability, and plantar pressure in Pes Planus. Journal of Sport Rehabilitation, 29(4), 436-440. https://doi.org/10.1123/js. 2018-0363

Yazdani, F., Razeghi, M., Karimi, M. T., Raeisi Shahraki, H., \& Salimi Bani, M. (2018). The influence of foot hyperpronation on pelvic biomechanics during stance phase of the gait: A biomechanical simulation study. Proceedings of the Institution of Mechanical Engineers, Part $\mathrm{H}$ : Journal of Engineering in Medicine, 232(7), 708-717. https://doi.org/10.1177/0954411918778077

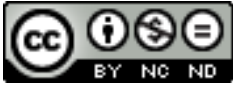

This work is licensed under a Attribution-NonCommercial-NoDerivatives 4.0 International (CC BY-NC-ND 4.0). 